\title{
Movimientos sociales rurales en tiempos neoliberales: antagonismos y subjetividades políticas en resistencias \\ Rural social movements in neoliberal times: antagonisms and political subjectivities in resistance
}

Oscar Soto

Universidad Nacional de Cuyo - Argentina

Mendoza, Argentina

sotooscarhumberto@gmail.com

\section{RESUMEN}

Este artículo realiza un análisis sobre la experiencia política del Movimiento Nacional Campesino Indígena-Somos Tierra, con la intención de caracterizar las modalidades de resistencias surgidas en los espacios rurales latinoamericanos, particularmente en Argentina. Se parte del supuesto de que en la praxis de los movimientos sociales/populares, en particular los movimientos campesinos-indígenas, se estructuran y re-configuran subjetividades políticas en procesos de resistencia, cuyas tramas de acción conforman otra episteme y una nueva cultura política que se evidencia entre otras cosas en los saberes que emergen de la labor política y los espacios colectivos construidos en el campo. A tal fin, se intenta reseñar los núcleos teórico-políticos que atraviesan la movilización popular latinoamericana desde el Movimiento Nacional Campesino Indígena- Somos Tierra, en tanto espacio de politicidades rurales que configuran una resistencia frontal a la fase neoliberal del capitalismo global.

Palabras claves: antagonismos; Somos Tierra; movimientos sociales; praxis; resistencias

\section{ABSTRACT}

This article analyses the political experience of the Movimiento Nacional Campesino Indígena - Somos Tierra, with the intention of characterizing the forms of resistance that have emerged in rural Latin America, particularly in Argentina. The hypothesis is that in the praxis of social/popular movements, in particular the peasant-indigenous movements, political subjectivities are structured and re-configured in processes of resistance, whose action networks form another episteme and a new political culture that is evident, among other things, in the knowledge that emerges from political work and the collective spaces built in the countryside. To this end, it is attempted to review the theoretical-political nuclei that cross the Latin American popular mobilization from the MNCl/Somos Tierra as a space of rural politics that configure a frontal resistance to the neoliberal phase of global capitalism.

Keywords: antagonisms; Somos Tierra; social movements; praxis; resistances 


\section{INTRODUCCIÓN}

El presente texto surge como continuidad de tratamiento del corpus teórico y el abordaje realizado en el marco de la Maestría en Estudios Latinoamericanos en la Universidad Nacional de Cuyo, Argentina, respecto de los movimientos sociales del mundo rural en América Latina. En tal sentido es que la propuesta consiste en, dar cuenta de una intuición teórico-político que rodea el proceso de investigación: la praxis de los movimientos sociales, en particular los movimientos campesinos-indígenas, estructuran y reconfiguran subjetividades políticas en procesos de resistencia, cuyas tramas de acción conforman otra episteme y una nueva cultura política que se evidencia entre otras cosas en los saberes que emergen de la labor política y los espacios colectivos construidos en el campo (Barbosa, 2015, p. 47). La dimensión de las prácticas y acciones del Movimiento Nacional Campesino Indígena - Somos Tierra (MNCl/Somos Tierra) son una explicitación de sentidos políticos que despliegan relaciones sociales más cooperativas, igualitarias, de respeto a la tierra, a la vez generan formas de disputas contrahegemónicas contra el capital y su faceta neoliberal, trascurridas en América Latina en la historia reciente.

En segunda instancia, se intenta re-pensar teóricamente los movimientos sociales/populares del mundo rural, justamente a partir de la particularidad latinoamericana de sus acciones sociopolíticas situadas: su capacidad de organización política y la puesta en cuestión de las lógicas de dominación. Así, se busca posibilitar una ruptura respecto de ciertas dinámicas hegemónicas de aproximación a las luchas sociales latinoamericanas. Esto es: más de una vez los debates del pensamiento crítico latinoamericano han recurrido a la puesta en cuestión de la acción colectiva de los sectores populares al calor de la conflictividad social reciente, en vistas de tensionar las brechas autonómicas y el traspaso de sus fronteras identitarias, que suelen ser repasadas, las más de las veces, orientadas hacia "una interpretación a-conflictiva de la política, vinculada a la preocupación por la gobernabilidad, la representación y los procesos de institucionalización” (Modonesi e Iglesias, 2016, p. 97). La propuesta se centra, entonces, en acentuar la cuestión del conflicto político-territorial, como elemento relevante para ampliar las re-lecturas posibles de la problemática de las transformaciones políticas y su relación con los movimientos sociales rurales; al tiempo que se recorre parte de las propuestas pedagógicopolíticas de estos últimos en su conformación clasista surgida en el seno de los antagonismos sociales y las búsquedas de alternativas contrahegemónicas al capital.

\section{METODOLOGÍA}

En el desarrollo de este trabajo se abren interrogantes que, por otro lado, no pretenden ser clausurados de manera total. Estas líneas giran en torno a un tipo de metodología no extractiva cuyas implicaciones determinan desde el inicio una ruptura epistemológica, en tanto se proponen conocer y reflexionar a partir del conocimiento que se construye con y desde una parte del movimiento campesino argentino. Se trata, entonces, de dar cuenta de estos/as sujetos/as sociopolíticos a los que comprende la lucha campesina en épocas neoliberales, sin -por ello- "extraer" un supuesto saber, antes bien co-construir desde las prácticas en el territorio.

A medida que se relatan experiencias, se remite necesariamente a la idea de "comunidades investigadasinvestigadoras" a las que el Movimiento Rural, y luego las Ligas Agrarias de Argentina, se referirían allá por los años 60 y 70 (Ferrara, 2007, p. 42). En este caso, se intenta reseñar los núcleos teórico-políticos que atraviesan la movilización popular latinoamericana desde el $\mathrm{MNCl} /$ Somos Tierra en cuanto espacio de comunidades rurales que configuran una resistencia frontal a la fase neoliberal del capitalismo global. Por todo ello, el proceso de investigación/acción aquí resumido responde a un trabajo mayor que es realizado como forma de combinación entre lo racional y lo vivencial de la tarea científico social (Fals Borda, 2015). Si bien se asume una tarea de intelección y observación desde las bases, vale apuntar que se han escogido algunas voces de sujetos y sujetas campesinas activistas al interior del movimiento campesino argentino. Las técnicas de construcción de datos han sido principalmente entrevistas (no estructuradas y en profundidad) y el análisis de la documentación colectiva producida por el $\mathrm{MNCl} /$ Somos Tierra, junto con la triangulación de lecturas del pensamiento crítico latinoamericano. Las entrevistas ayudaron a reconstruir desde los/as sujetos/as campesinos la experiencia, valoraciones y 
percepciones de tales prácticas en el periodo abordado; a los fines de discernir las características de esas acciones en el seno de los movimientos sociales/populares del mundo rural.

\section{DISCUSIONES \\ 3.1 Estudios sobre los movimientos sociales}

La problemática social y el deterioro de las condiciones de vida, que sobrevienen a la consolidación del capitalismo global, han dado lugar a un prolífico estudio sobre los fenómenos societales y el respectivo desarrollo de teorías de acción colectiva (Tarrow, 1997) o nuevos paradigmas en los que el campo de acción de los nuevos movimientos sociales remiten a espacios políticos no institucionales, no previstos por la democracia liberal ni el Estado de Bienestar (Offe, 1988, p. 174), caracterizados por la emergencia de la protesta social callejera, manifestaciones, huelgas e instancias de participación social directa, o como dice Clauss Offe marcados por contenidos dominantes, como el interés por el territorio-físico, el mundo de vida, el cuerpo, la salud, las identidades sexuales y culturales (Offe, 1998, p. 177). El estudio de la movilización social adquiere, desde los años ' 60 del siglo pasado en adelante, una impronta relevante en el cuerpo teórico de las ciencias sociales, dando lugar a nuevas teorías acerca de la sociedad civil (Gohn, 1997), incluso llegando a proponer al fenómeno de los movimientos sociales como un sector o subsistema de lo social (Melucci, 1986).

La raigambre histórica del concepto de movimientos sociales tiene vínculos con la temprana expansión burguesa desde la Revolución Francesa hasta la escalada de participación obrero-burguesa de 1848, siendo luego de uso frecuente a la hora de estudiar al movimiento obrero en la fase del capitalismo industrial (Palumbo, 2014). Sin embargo, con el paso del tiempo, resulta cada vez más hegemónica la utilización de la categoría movimiento social para remitir explicaciones respecto de la conflictividad social latente desde mediados de los años sesenta y setenta en adelante. Particularmente en Europa se disemina, a partir de la visibilidad de manifestaciones pacifistas, ecologistas y feministas, entre otras, una cierta idea de traspaso histórico hacia un tipo de sociedad "pos-industrial" cuya característica destacable seria la evaporación del antagonismo clasista de épocas previas, o cierto requerimiento en la necesidad conceptualizar movimientos, antes que "clases" sociales (Touraine, 1991).

Si bien la existencia de lecturas clásicas sobre la movilización social encuentra un conjunto de elementos que las relaciona con Europa y Norteamérica (Gohn, 1997), el interés de nuestra perspectiva es justamente avanzar por sobre la hegemonía teórica de cierto tipo de análisis geopolíticamente colonial, aun vigente en las ciencias sociales, -esto será retomado luego-. Ahora bien, entre las formas de abordaje de la protesta social y las aproximaciones a los movimientos de la sociedad civil, redundará cierta revisión de autonomía individual y accionar no convencional en los novedosos movimientos sociales, para definir su demarcación respecto de la tradición crítica del activismo obrero clásico. Seoane, Algranatti y Taddei (2009) dirán que la noción teórica de nuevos movimientos sociales ya presente en Europa, particularmente en la llamada Escuela de los Nuevos Movimientos Sociales, apuntará a comprender que:

\footnotetext{
Dichos “nuevos movimientos sociales” no sólo se diferenciaban, sino que además tendían a contraponerse al movimiento obrero demonizado ahora por su arcaísmo. En esta perspectiva, los movimientos de clase dejaban lugar a la aparición de nuevos movimientos caracterizados por orientarse a la disputa por los recursos culturales o simbólicos, formulándose de esta manera una crítica a los esquemas interpretativos del paradigma marxista en particular, y del pensamiento crítico en general. Se postulaba así el abandono de la consideración del antagonismo de clase capital-trabajo y de las formas de explotación inherentes a esta relación social bajo una pretendida superación del mismo por corresponder a un modelo social del pasado. (Seoane et al., 2009, p. 9)
}

Pese al intento teórico de desmarcar movimiento y clase social, el debate político en las periferias de la ciencia occidental apunta hacia sujetos de resistencia que interpelan las categorías y las 
conceptualizaciones del conflicto socio-político. Se señala esto a cuento de que en las tradiciones de estudio de los movimientos sociales, identificadas en el "individualismo metodológico", tanto las que abordan la protesta y la acción colectiva (predominantemente norteamericanas), como las enroladas en la cuestión de la identidad (en su mayoría de origen europeo) hay cierta tendencia a una visión dicotómica y una cosificación estática de la realidad social, que sitúa a viejos y nuevos movimientos sociales enfrentados (Galafassi, 2006, p. 39-53).

\title{
3.2 Re-leer desde Nuestra América
}

En realidad los procesos sociales observados desde América Latina merecen una atención particular cuando se trata de resituar el debate sobre las resistencias sociales históricas; es decir, frente a la mirada fenoménica tradicional de las teorías que buscan conjugar individualismo metodológico y sistema social bajo las conceptualizaciones de "acción colectiva", "movimiento social" o "nuevos movimientos sociales" (Galafassi, 2017, p. 14), resulta recurrente la necesaria colocación del antagonismo social como elemento, sino estructurante al menos condicionante, de las conflictividades en cualquier sociedad de clases. Respecto de la cuestión de clases y los movimientos sociales se apunta aquí a resaltar la continuidad de la confrontación capital/trabajo -el antagonismo social- como dispositivo que articula la disputa general en los modelos económico-sociales, sin dejar de incorporar la acción de los sujetos (sujetos campesinos e indígenas como aquí se propone). Dicho en los términos de Guido Galafassi:

\begin{abstract}
Antagonismo social que, en cambio, se expresa tanto en los procesos de transformación como en las prácticas cotidianas constituyéndose en dinámicas inherentes al proceso de la sociedad en su conjunto, siendo las clases en tanto pilar de la lucha de clases, las categorías de análisis fundantes [...] la categoría "lucha de clases" sigue siendo clave para entender la conflictividad en cualquier sociedad de clases (claro, bajo la premisa de saldar la deuda intelectual respecto a la necesaria consideración de la acción de los sujetos). Más, no se puede dejar de puntualizar que el problema se ha generado con la esencialización y absolutización de la lucha de clases como paradigma explicativo de todo y más, impidiendo de esta manera ver la multiplicidad de expresiones y manifestaciones de las relaciones sociales que se dan en el marco de la complejidad creciente de una sociedad de clases (2017, p. 13-15).
\end{abstract}

Entre el variado repertorio de aproximación teórica a los movimientos sociales, desde las perspectivas de Parsons, Smelser, pasando por la escuela de "movilización de recursos" de Olson, Mc Carthy, y Zald; las nociones de "oportunidades políticas" de Tarrow y Tilly, hasta las contribuciones de Offe, Melluci y Touraine en los años 70 y 80 sobre los "NMS" -nuevos movimientos sociales- (Seoane, Taddei y Algranatti, 2009, p. 5-6); el conjunto de miradas suele acentuar el fenómeno de protesta social de manera novedosa, casi como articulando a un "nuevo sujeto político" como tal. El mismo Clauss Offe (1988, p. 239) en su trabajo sobre partidos políticos y movimientos sociales, arribará a la idea de que, en la Europa occidental de su análisis, la clave del conflicto político se sitúa en la confrontación entre fuerzas de "dentro" y fuerzas de "fuera" de la definición convencional de la política y sus actores colectivos.

De cualquier forma, el pretendido carácter novedoso en el análisis de los movimientos de acción colectiva, comprendido con cierta distinción -en algunos casos puntualmente como quiebre- respecto del recorrido histórico de las clases trabajadoras, en tanto componente estructural de las sociedades capitalistas, resulta cuanto menos una arista a revisar y a la cual prestar la debida atención epistemológica y teórica. En términos de Guido Galafassi, apuntamos a que:

Las perspectivas que resaltan la clase en tanto construcción de relaciones subjetivas emergen más fuertemente en las últimas décadas con la intención justamente de contrarrestar el carácter determinativo de la clase en forma exclusiva por sobre los sujetos. Y es de interés esta tensión porque es aquella que me permitirá luego poder articularla en 
una noción de conflicto dialéctico que pueda dar una mejor cuenta de la complejidad de variantes que asume la conflictividad en una sociedad de clases (con el antagonismo como característica clave) y que se visibiliza más cabalmente en las últimas décadas, montada sobre una diversidad de contradicciones y en donde la dimensión cultural de consensocoerción de construcción de identidad (conciencia) cobra una importancia fuerte y que en muchos casos van más allá de la primaria y fundamental contradicción presente entre el capital y el trabajo, sin que esto implique negarla, ignorarla o minimizarla (2017, p. 15-16).

Lo sucedido desde América Latina en los contextos de resistencia social reciente, contribuye a reformular el sentido con el que son leídos los movimientos sociales y la productividad emancipatoria de sus prácticas sociales; consecuencia de ello es que, en nuestra comprensión, las ciencias sociales están íntimamente ligadas a la suerte de las luchas sociales. Precisamente la noción de ruptura radical entre razón y cuerpo representa cabalmente una de las aristas centrales del avasallamiento de la modernidad sobre las esferas sociales de vida; particularmente en lo relativo al conocimiento y la producción de saber (Lander, 2000). La distinción tajante entre sujeto y objeto de conocimiento encuentra en la lógica colonial/moderno sustento práctico, a su vez -por esas mismas razones- una forma dualista de comprensión del mundo se consolida como elemento distintivo de la sociedad occidental. De ello, las ciencias sociales tienen una cuota parte de alcance en el drama moderno.

Es, en este último sentido, que la modernidad resulta un escenario de acción política al tiempo que una clave de interpretación geopolítica y epistémica; dicho en términos de Guido Galafassi -nuevamenteel binomio movilización social/modernidad redundan en procesos de articulación histórica que dan sentido y sustento a sus lógicas:

\begin{abstract}
La historia de la modernidad es la historia de la movilización social, la modernidad nace o se expresa materialmente a partir de procesos de la movilización y el cambio, la revolución inglesa y francesa dan forma a los inicios de la modernidad y luego esta se va expandiendo al resto del mundo a través de distintos procesos de ocupación y dominación que generan dialécticamente nuevos procesos de movilización, dándose incluso en muchos casos procesos revolucionarios también. Por lo tanto, el estudio de los procesos de movilización social es en parte el estudio de la modernidad y viceversa. Así, los movimientos sociales son parte inherente de la modernidad, son producto y productores de la modernidad y son la expresión de las cambiantes condiciones, estructuras y procesos de la modernidad. Los procesos de industrialización, urbanización, acumulación capitalista y desarrollo poscapitalista son el entramado dialéctico con el cual los movimientos sociales interaccionan conformándose y conformándolos (Galafassi, 2006, p. 37).
\end{abstract}

\title{
3.3 Viejos movimientos en resistencia e historia reciente ${ }^{T}$
}

La cuestión del fin de la política en las calles o la desaparición de las clases trabajadoras como sujeto histórico en las ciencias sociales y la perspectiva teórica de los años 80's (Iñigo Carrera, 2008) estuvo ligada al auge del análisis de los nuevos movimientos sociales como "protagonistas privilegiados" de la protesta social contra el neoliberalismo. En cierta medida la clave de lectura social que buscaba escapar al determinismo economicista típico de años anteriores, había tendido a la idealización de la espontaneidad en la organización de la sociedad civil. Sin embargo, en este trabajo se parte de la tesis de que los movimientos sociales del mundo rural, en particular el conjunto de organizaciones de base campesinas e indígenas en América Latina, re-configuran subjetividades políticas en procesos de resistencia, cuyas tramas de acción conforman otra episteme y una nueva cultura política que se evidencia entre otras cosas en los saberes que emergen de la labor política y los espacios colectivos

1 Aquí se considera la idea del "pasado reciente" como forma de percibir las historias cercanas de Nuestra América por fuera del discurso coyuntural, los relatos presentistas y las visiones despolitizadas y a-históricas de los sucesos contemporáneos (Caetano, 2006). 
construidos en el Campo.

La especificidad de la insurrección societal latinoamericana remite a un conjunto de aspectos teóricos otros, respecto de la mirada del norte global, para discernir el carácter de la protesta social y la acción colectiva, en especial la del universo campesino-indígena. Si bien la estadística en perspectiva histórica remite a constatar la persistencia actual del sector asalariado en la lucha por reivindicaciones sociales (Iñigo Carrera, 2008, p. 79), además de que la base que la constituye, en muchos casos, es de aspectos económico-sociales y no situaciones puramente socioculturales; no se debe perder de vista que en América Latina el movimiento social se desarrolla como movimiento político en los marcos de un tipo de Estado ampliado (Autor, 2019). A continuación, delineamos los apuntes que complementan este estudio sobre los movimientos campesinos, en particular el caso del Movimiento Nacional Campesino Indígena - Somos Tierra.

\section{RESULTADOS \\ 4.1 Movimientos campesinos, proyectos educativos y contrahegemonía}

Los movimientos sociales campesinos/rurales latinoamericanos se caracterizan por el despliegue de un conjunto de prácticas cuya dimensión ha sido relevante en el proceso de impugnación al capitalismo y su fase neoliberal en América Latina. A partir de lo que se ha planteado hasta aquí, importa retomar la necesidad de avanzar por sobre la lectura dicotómica que contrapone la perspectiva de la constitución subjetiva de los movimientos sociales con las miradas que enfatizan los condicionamientos económicoestructurales (Seoane et al., 2009, p. 11) como elemento para descolonizar el pensamiento crítico y las ciencias sociales en América Latina. El análisis de los movimientos sociales en Nuestra América, debe implicar una doble ruptura epistemológica y política en relación a las escuelas de pensamiento tradicionales.

En primer lugar, la noción de movimientos sociales en tanto sujetos educativos-políticos y espacios de construcción de una episteme que produce saberes alternativos y proyectos políticos contrahegemónicos (Barbosa, 2013a, p. 124), es una característica central de los movimientos campesinos-indígenas en la ocupación del conflicto territorial concreto y en la resignificación de la problemática de la explotación como clases sociales oprimidas, en el actual sistema capitalista neoliberal. El proceso de resistencia social y política latinoamericana -siguiendo a Pinheiro Barbosa (2013b)- propuesta por pueblos campesinos, indígenas, afrodescendientes, quilombolas y ribereños, como aquellos desplazados y empobrecidos en las grandes ciudades, constituyen el reverso de las secuelas que ha dejado la colonización iberoamericana, como así también la agudización de las contradicciones y antagonismos sociales actuales. En tal sentido es, que al re-pensar Latinoamérica, los sujetos sociales campesinos/indígenas organizados representan la emergencia de un mosaico de rebeldías que se expresan en otras semánticas y dispositivos de lucha ideológica. De manera tal que sus prácticas desafían la unilateralidad hegemónica de la colonialidad, al tiempo que exponen la continuidad histórica de una "profunda contradicción estructural subyacente al y propia del capital" (Barbosa, 2013b, p. 24).

Las demandas articuladas que encarnan esos pueblos organizados en movimientos sociales expresan, contrariamente a lo que se suele asumir desde las "teorías de los nuevos movimientos sociales" a la que se ha hecho referencia, la centralidad de las clases sociales en contextos de dependencia ${ }^{2}$. Es decir que, tanto las formas de resistencia como las alternativas pedagógico-políticas que los movimientos sociales campesinos-indígenas desarrollan en América Latina, resultan una grafía de impugnación al modelo económico-político del capitalismo al tiempo que elaboran una critica del tipo de relaciones ideológicas que atraviesan de múltiples maneras las modalidades de conciencia y voluntad de los sujetos; y las luchas locales dan cuenta de esto en la coyuntura continental, o dicho en los términos de Barbosa,

2 Pensando en Argentina, es sugerente el enfoque de Nicolás Iñigo Carrera (2008, p. 85) "partimos de saber que es un país dependiente donde el capitalismo, medido por la extensión de las relaciones sociales que le son propias, está desarrollado. Esta caracterización general nos señala dos líneas de confrontación que están potencialmente siempre presentes: la que hace a la dimensión liberación nacional-dependencia (nación imperialismo) y la que hace a la dimensión liberación social-explotación (expropiados-propietarios de condiciones materiales de existencia)" 
...denuncian de par a par las múltiples formas de sojuzgar propias de un modelo políticoeconómico que edificó su dominación mas allá del campo económico, haciendo raíces profundamente arraigadas a esquemas simbólicos-ideológicos que dan sostenimiento a la dominación vivida en nuestros días (2013b, p. 24).

\title{
4.2 El Movimiento Nacional Campesino Indígena-Somos Tierra en Argentina
}

Dado el auge neoliberal en la región, el deterioro de las condiciones de vida de las poblaciones rurales tuvo como resultado el surgimiento de comunidades de base campesina e indígena, que se organizarían para resistir los crecientes desalojos en toda la región. Un grupo numeroso de las organizaciones campesinas multiplicadas por las provincias argentinas dieron nacimiento desde finales de los 90 y principios de los 2000, al Movimiento Nacional Campesino Indígena $(\mathrm{MNCl})^{3}$, considerado por muchos como la más relevante propuesta de organización política campesina en Argentina desde las Ligas Agrarias de los años setenta (Pinto, 2015, p. 168).

\begin{abstract}
El $\mathrm{MNCl}$ es un movimiento que supera ya los 10 años de organización del campesinado indígena en varias provincias del territorio argentino, bajo las banderas de la organización popular, la reforma agraria integral y la soberanía alimentaria, donde en el contexto de una nación con su población fuertemente concentrada en las ciudades, se vislumbra la importancia de la vuelta al campo como un claro desafío. El MNCI tuvo su primer congreso en 2010 bajo el lema: Somos Tierra, para alimentar a los Pueblos Desde su lanzamiento en abril de 2014 el VI Congreso de la CLOC LVC, con el lema: "Contra el Capitalismo, por la soberanía de 81 nuestros pueblos. iAmérica Unida Sigue en Lucha!, viene siendo un camino con debates y reflexiones a nivel nacional, regional y continental, sobre los principales desafíos y preocupaciones del mundo agrario y popular, situándonos sobre la tarea del sector y al aporte al proyecto popular latinoamericano y caribeño en este momento histórico (CLOC, 2015, p. 3).
\end{abstract}

Una característica distintiva de este movimiento fue la particularidad de articulación de las franjas más excluidas de los sectores campesinos junto con los segmentos indígenas o descendientes de indígenas que históricamente, como ya se indicó, se organizaban por separado. A la vez que los unificó una modalidad de lucha, la agricultura transgénico-intensiva y de los monocultivos como proyecto de país (Pinto, 2015, p.193) fue lo que determinó la unidad de sus resistencias y una nueva subjetivación política. Fue precisamente a principio del año 2000 que muchas organizaciones de base campesino-indígena dieron forma al $\mathrm{MNCl}$ y éste a su vez se consolidó como una organización miembro de la Coordinadora Latinoamericana de Organizaciones del Campo (CLOC). Su dinámica política enmarcada en La Vía Campesina Internacional constituye una coalición antiimperialista (Bartra, 2010, p. 6) y una convergencia fundamental de la resistencia global al capital, en contextos de agravamiento del extractivismo y el acaparamiento de territorios rurales.

Formado por organizaciones de 10 provincias representantes de prácticamente todas las regiones del país, con una base social compuesta por poco más de 20 mil familias, el Movimiento nace de la junción de varios movimientos regionales-provinciales [...] El MNCl es formado por las siguientes organizaciones: Movimiento Campesino de Santiago del Estero (MOCASE-VC), el Movimiento Campesino de Córdoba (MCC), la Unión de Trabajadores Rurales Sin Tierra (UST) de Mendoza y San Juan, la Red Puna de Jujuy, Encuentro Calchaquí de Salta, Mesa Campesina del Norte Neuquino, Movimiento Giros de Rosario, Coordinadora de Organizaciones de Trabajadores Rurales Unidos de Misiones (COTRUM) y Organizaciones

3 Se debe tener en cuenta que las organizaciones que estructural el $\mathrm{MNCl}$ como tales anteceden en el tiempo la formalidad de la articulación nacional. 
Comunitarias Urbanas de la Ciudad Autónoma de Buenos Aires y la Provincia de Buenos

Aires (Pinto, 2015, p. 192).

En los últimos años se ha dado en la región, tanto en el estudio de los movimientos sociales como en la práctica misma de las luchas populares, un cierto desplazamiento semántico desde la noción de movimiento social a la caracterización de movimientos populares latinoamericanos (Palumbo, 2016, p. 224). Puntualmente en lo que se refiere a los procesos formativos de los movimientos, se han desarrollado distintas elaboraciones teóricas orgánicas a los procesos políticos en curso, entre las que se resalta la emergencia de una disputa epistémica llevada a cabo por los movimientos sociales-populares en la construcción de saberes y formas de educación popular alternativa. Se constata que, en el acontecer de las resistencias populares en América Latina, los proyectos políticos-educativos de los movimientos apuntan a poner en cuestión la pasividad hegemónica que la misma pedagogía tradicional le asigna bajo el imperio del capital. Dicho de otra forma, una vía de expresión del antagonismo social y la tensión de clases en la actual coyuntura regional, se materializa en las disputas pedagógico-políticas enunciadas:

Un mirar panorámico sobre el continente nos permite vislumbrar los indicios de un proyecto emancipador, vinculado a un papel político conferido a la Educación, manifiestos en: la trayectoria del Sector de Educación del MST; en la propuesta de creación de la Universidad del Sur; en la expresiva experiencia del Método de Alfabetización cubano, "Sí, Yo Puedo!", sobre todo con los pueblos originarios; en las Escuelas Autónomas Rebeldes Zapatistas, entre otras propuestas que se han consolidado y avanzado gradualmente, testigos vivos de que el "paradigma emancipador para América Latina” tiene un pie en la Educación, camino de transformación cultural radical y necesaria a nuestro continente (Barbosa, 2009, p.6).

De estos procesos, a continuación, se resalta el desarrollo de las Escuelas Campesinas de Agroecología, en particular la praxis educativa de los movimientos que integran La Vía Campesina (LVC) y la Coordinadora Latinoamericana de Organizaciones del Campo (CLOC), consecuencia directa de las luchas de resistencia producto de la proletarización rural y el avance sobre los territorios campesinosindígenas en América Latina. Brevemente se analizará la lucha del MNCl/Somos Tierra.

\subsection{Recuperación de saberes y educación campesina como antagonismo}

El proyecto de educación popular del $\mathrm{MNCl} /$ Somos Tierra apunta a la recuperación de la memoria histórica de los territorios campesinos y la praxis del dialogo de saberes populares rurales con conocimientos teórico-políticos. Particularmente por ser parte de las Escuelas de Formación en Agroecológica y los Institutos Agroecológicos Latinoamericanos (IALAS). La propuesta de garantizar un proceso de formación rural desde el sur, como criterio práctico para "masificar la formación en Agroecología y multiplicar los líderes e intelectuales orgánicos de los movimientos sociales" a la vez que "consolidar la Agroecología como orientación para la producción de alimentos saludables, libres de agrotóxicos y transgénicos para conquistar la Soberanía Alimentaria” (La Vía Campesina, 2015), es una de las banderas de lucha contrahegemónica de la CLOC y todos los movimientos campesinos/indígenas que componen La Vía.

En Mendoza el Centro de Educación, Formación e Investigación Campesina (CEFIC) de la Unión de Trabajadores Rurales sin Tierra-MNCI/Somos Tierra surge, como toda organización, por una necesidad: construir una escuela desde el sujeto campesino/indígena. La metodología que busca recuperar los saberes territoriales y corporales de mujeres y hombres del campo, se plantea desde el CEFIC en los siguientes términos: un Tiempo Escuela, un Tiempo Comunidad, un Tiempo de talleres y un Tiempo de Mística (Greco et al, 2019). Toda esta temporalidad permite comprender a la educación como proceso formativo y organizativo, contrapuesto a la invasión cultural que realiza el capital. Estos Tiempos, a su vez, son acompañados por estudiantes y profesores de la Universidad; siendo, en sentido estricto, una forma de educación en el campo y para el campo, articulada políticamente en sentido de alianzas sociales 


\title{
contrahegemónicas.
}

El neoliberalismo en América Latina en contextos de reactivaciones autoritarias, lejos de promover la ausencia del aparato del Estado, constituye una garantía para la gestión externa de los territorios. En gran medida son las normas del mercado las que configuran las reglas públicas de producción y desarrollo de los espacios. Sobre esa contraposición de capitalismo versus campesinado que delinea la estructura el MNCI/Somos Tierra, Germán, educador y militante de la organización, lo define así:

Yo creo que, tanto en lo general como en lo coyuntural, los principios de la organización, es una cuestión opuesta a lo que es el sistema capitalista en general, es de alguna manera una alternativa a eso, y desde allí es que se plantea un tipo de producción diferente, que sea colectivo, que sea agroecológico y una mirada desde los Derechos Humanos también, desde la educación popular, es decir, una mirada puesta en los sectores populares. Esto está totalmente contrapuesto al sistema capitalista, y por ende se encuentra con una pared a nivel político en nuestro país, sobre todo en los tiempos que corren, porque está enfrentado. Nosotros como organización planteamos una transformación desnaturalizando la realidad actual, desde el punto de vista del campo, campo entendido como la gente que trabaja la tierra, planteamos un modo de trabajo sin patrón, de manera agroecológica, colectiva, y eso es una manera de incidir en la transformación de la realidad, de por sí formar parte de una experiencia así supongo que ayuda, por un lado a conectarse con experiencias parecidas, porque hay otras organizaciones que están trabajando las mismas temáticas, y por el otro lado, contraponerlo con este sistema que vivimos, el sistema tradicional capitalista (Entrevista personal, realizada 3/08/18).

Como se plantó al inicio de este trabajo, el análisis de los nuevos movimientos sociales en tanto actores relevantes del conflicto social, configura una novedad de "acción contenciosa y colectiva contemporánea" que se relaciona directamente, aunque no de manera unilateral, con la fase capitalista neoliberal en curso y con la especificidad latinoamericana -y del mundo periférico en general- (Seoane, Taddei, Algranati, 2018, p. 12). Todo lo cual, a su vez, resulta necesario para discernir el carácter de la protesta social, en especial la acción colectiva del universo campesino-indígena. Dhana militante de la UST-MNCI/Somos Tierra lo propone así:

\begin{abstract}
Una de las herramientas, que nosotros como UST, y como $\mathrm{MNCI}$, que creemos que sí puede dar un avance, para esta sociedad en que vivimos actualmente, sobre todo para el campesinado y que sostiene nuestra bandera de lucha, es la reforma agraria popular y la soberanía alimentaria, y en eso entran un montón de cosas. En lo que es la soberanía alimentaria, cómo producir alimentos sanos agroecológicamente, y cómo eso lo llevamos a la práctica, todos los días, en las escuelas de agroecología, que no hay solamente acá en Mendoza, sino en el país, y los espacios de formación que tenemos a diario, los campamentos, las escuelas de formación política, que también existen a nivel continental, como es América Latina. Estar en constante aprendiendo y desaprendiendo un montón de cosas, en cuanto a lo productivo, cómo producir alimentos sanos, para quienes, cómo hacer que realmente ese alimento que se produce llegue a las personas que queremos que lleguen, cómo circula también en el mismo lugar dónde uno está [...] (Entrevista personal, realizada el 20/11/18).
\end{abstract}

Tal vez allí radique un punto de indagación para conceptualizar el poder surgido de las clases subalternas. Dicho de otra forma, una vía de expresión del antagonismo social y la tensión de clases en la actualidad regional, se materializa en las disputas pedagógico-políticas que definen los contornos de un poder plebeyo. Apropiándose de su lugar político como locus de conformación de una episteme, el movimiento campesino argentino congrega un léxico particular que demarca nuevos conceptos nacidos desde su lengua, cultura, saber y experiencia. Se redefinen, así, las formas de interpretación de la realidad social y de ocurrencia sobre ella. Asimismo, se redimensiona el lugar de inscripción de la investigación y de la construcción del conocimiento en cuanto instrumento de lucha y de transformación social, lo que 
implica reconocer a estos movimientos sociales/populares de base campesina, como sujetos educativopolíticos (Barbosa, 2013a, p. 139).

\begin{abstract}
Bueno, según mi entender, el Movimiento parte de una realidad social, pero también política, y ante eso es una propuesta política para transformar la realidad social. Es decir, la UST y el MNCI tiene una mirada política, contrapuesta a la política capitalista y eso es político...que intenta transformar la realidad social, para que también la sociedad recupere la capacidad de la participación política. Porque no se trata de operar sobre una sociedad estática, sino que la sociedad se re-politice, conforme a procesos que han ido a contrapelo de esto, que han intentado que la sociedad se despolitice, termine naturalizando la realidad, y de alguna manera no cuestionándose la realidad que tenemos. (Entrevista personal, realizada el 20/11/2018).
\end{abstract}

Las tensiones propias que atraviesan los movimientos populares latinoamericanos, desde las más cotidianas hasta aquellas menos frecuentes, son enfrentadas por una organización política que asume el desafío de la resistencia rural, en un contexto de mercantilización de las relaciones agrarias y de despoblamiento de los espacios campesinos. La educación popular con una perspectiva emancipatoria enfrenta aislamiento y despolitización. Es desde allí que se articula con el Estado, las dinámicas pedagógicas del CEFIC, no sin confrontaciones y conflictos de poder, pero con vistas a la concreción de un tipo de educación liberadora.

El MNCl/Somos Tierra asume un tipo de praxis educativa que pretende una relación dialéctica entre sujeto personal y sujeto colectivo, o entre autonomía y comunidad (Barbosa, 2013a, p. 135); praxis necesaria para la construcción de una forma de comunidad que consolide una revolución de las relaciones sociales, la soberanía alimentaria y la reforma agraria integral. El proceso de disputa sociopolítica y cultural emprendido por la el $\mathrm{MNCl} /$ Somos Tierra, implica un debate ideológico con raíces en el pensamiento pedagógico latinoamericano. En ese mismo sentido es que estas prácticas amplían el campo de estudios de los antagonismos y las construcciones hegemónicas en el vasto mundo de los movimientos sociales/ populares.

\title{
5. CONCLUSIONES
}

Este texto reúne apuntes provisorios de un trabajo de investigación en proceso. Lo sucedido desde América Latina en los contextos de resistencia social reciente, contribuye a reformular el sentido con el que son leídos los movimientos sociales y la productividad emancipatoria de sus prácticas sociales; consecuencia de ello es que, la especificidad de la insurrección societal latinoamericana remite a un conjunto de aspectos teóricos otros, respecto de la mirada del norte global, para discernir el carácter de la protesta social y la acción colectiva, en especial la del universo campesino-indígena.

La noción de movimientos sociales en tanto sujetos educativos-políticos y espacios de construcción de una episteme que produce saberes alternativos y proyectos políticos contrahegemónicos, constituye una característica central de los movimientos campesinos-indígenas en la ocupación del conflicto territorial concreto y en la re-significación de la problemática de la explotación como clases sociales oprimidas, en el actual sistema capitalista neoliberal. Así presentados, los movimientos sociales desde América Latina se estructuran en torno de una disputa de sentidos que representan una erosión a las formas de dominación del capital, pero llevadas a cabo por vía de la puesta en cuestión de sus elementos ideológico-políticos. En el caso de los movimientos sociales del mundo rural, entre los que el campesinado latinoamericano y los movimientos indígenas resaltan por la vitalidad sus luchas políticas, la cuestión de las propuestas educativo/políticas recrea formas de articulación social, una praxis política disruptiva y nueva modalidad para releer las tramas de acción de los movimientos sociales.

A partir de la experiencia de lucha política del MNCI/Somos Tierra, se puede reafirmar que la articulación de pedagogías populares y proyectos pedagógicos como el CEFIC del MNCI/Somos Tierra, es una de las muchas dinámicas de contra hegemonía que se construyen desde nuestro sur global; es al mismo tiempo 
una búsqueda por recuperar saberes y formas culturales de vida alternativas a las lógicas dominantes en tanto re-organización del trabajo rural y re-producción del campesinado como clase social.

En los últimos años se ha dado en la región, tanto en el estudio de los movimientos sociales como en la práctica misma de las luchas populares, un cierto desplazamiento semántico desde la noción de movimiento social a la caracterización de movimientos populares latinoamericanos. Se verificó, en sentido práctico, que, en el acontecer de las resistencias populares en América Latina, los proyectos políticoseducativos de los movimientos apuntan a colocar una vía de expresión del antagonismo social y la tensión de clases en la actual coyuntura regional. Es por ello que se indagó aquí la cuestión del conflicto político-territorial, como elemento relevante para ampliar las re-lecturas posibles de la problemática de las transformaciones políticas y su relación con los movimientos sociales rurales, al tiempo que se recorrió las propuestas pedagógico-políticas de estos últimos, en tanto espacios que re-crean nuevas estrategias políticas y la (re)emergencia de subjetividades colectivas en lucha por el territorio.

Finalmente, respecto de la cuestión de clases y los movimientos sociales es preciso resaltar la continuidad de la confrontación capital/trabajo -el antagonismo social- como parte de un dispositivo que articula la disputa general en los modelos económico-sociales, sin dejar de incorporar la acción de los/as sujetos/ as (sujetos/as campesinas e indígenas como aquí se propone).

\section{REFERENCIAS}

Barbosa, L. (2015). Educación, resistencia y movimientos sociales: la praxis educativo-política de los Sin Tierra y de los Zapatistas. (Tesis doctoral). Universidad Nacional Autónoma de México, México.

Barbosa, L. (2013a). Los movimientos sociales como sujetos educativos-políticos. En, M, Gomez Sollano y Z, Corenstein (Comps.) Reconfiguración de lo educativo en América Latina. Experiencias pedagógicas alternativas (pp. 121-164). Universidad Autónoma de México.

Barbosa, L. (2013b). Educación, movimientos sociales y Estado en América Latina: Estudio analítico de las experiencias de resistencia contra-hegemónica en Brasil y México. [Tesis doctoral, UNAM] Repositorio institucional UNAM. https://cutt.ly/bh3FmoQ

Barbosa, L. (2009). Movimientos sociales, protesta social y educación. Vías de acciones contrahegemónicas para la construcción de la democracia latinoamericana [Ponencia]. XXVII Congreso de la Asociación Latinoamericana de Sociología. VIII Jornadas de Sociología de la Universidad de Buenos Aires, Argentina. http://cdsa. aacademica.org/ooo-062/1657.pdf

Bartra, A. (2010). Campesindios. Aproximaciones a los campesinos de un continente colonizado. Memoria, Revista de Política y Cultura (248), 4-13.

Caetano, G. (2006). Fundamentación general del Grupo de Trabajo sobre Historia Reciente. En, G. Caetano (Comp.) Sujetos sociales y nuevas formas de protesta en la historia reciente de América Latina (pp. 9-22). CLACSO.

CLOC-Coordinadora Latinoamericana de Organizaciones del Campo (2015). Documento de trabajo interno de la CLOC. http://www.cloc-viacampesina.net/

Fals Borda, O. (2015). Una sociología sentipensante para América Latina. Siglo XXI Editores- CLACSO.

Galafassi, G. (2017). Conflictividad social, contradicción y complejidad: entre las clases y los movimientos sociales. En, G. Galafassi y S. Puricelli (Comps.), Perspectivas críticas sobre la conflictividad social. Extramuros Ediciones- Theomai Libros y GEACH.

Galafassi, G. (2006). Cuando el árbol no deja ver el bosque. Neofuncionalismo y posmodernidad en los estudios sobre movimientos sociales. Revista Theomai, (14), segundo semestre, 37-58.

Gohn, M. (1997). Teoria dos movimentos Sociais. Paradigmas clássicos e contemporáneos. Edições Loyola.

Greco, M., Peterle, R., Cuoto, M., Bonomo, C., et al. (2019). Educación rural y territorios en disputa: la alternancia como propuesta pedagógica. Revista Estudios de Extensión en Humanidades E+E, (6)7, 76-91. https://revistas. unc.edu.ar/index.php/EEH/article/view/24187

Iñigo Carrera, N. (2008). Algunos instrumentos para el análisis de las luchas populares en la llamada Historia Reciente. En, M. López Maya, N. Iñigo Carrera y P. Calveriro (Comps.) Luchas contrahegemónicas y cambios políticos recientes de América Latina, (pp. 77-94). CLACSO

La Vía Campesina (2015). Agroecología Campesina por la Soberanía Alimentaria y la Madre Tierra. Experiencias de la Vía Campesina. https://viacampesina.org/es/agroecologia-campesina-para-la-soberania-alimentaria-y-lamadre-tierra-experiencias-de-la-via-campesina-ya-disponible/ 
Lander, E. (2000). Ciencias sociales: saberes coloniales y eurocéntricos. En, E. Lander (Comp.) La colonialidad del saber: eurocentrismo y ciencias sociales Perspectivas latinoamericana. (pp. 4-23). CLACSO

Melucci, A. (1986). Las teorías de los movimientos sociales. Revista Estudios Políticos, 4(1), 92-101. http://dx.doi. org/10.22201/fcpys.24484903e.1986.2.60047

Modonesi, M., e Iglesias, M. (2016). Perspectivas teóricas para el estudio de los movimientos sociopolíticos en América Latina: ¿cambio de época o década perdida? De Raíz Diversa, 3(5), 95-124. http://dx.doi. org/10.22201/ppela.24487988e.2016.5.58502

Offe, C. (1988). Partidos políticos y nuevos movimientos sociales. Sistema.

Palumbo, M. (2016). Educación en movimientos populares rurales: un estado del arte. Revista Historia de la Educación Latinoamericana, 18(26), 219-240. https://doi.org/10.19053/01227238.4373

Palumbo, M. (2014) Un desplazamiento semántico, político y geográfico en la tradición de estudios sobre Movimientos Sociales: Aportes del concepto de movimiento popular. Estudios (32), 25-48. https://revistas. unc.edu.ar/index.php/restudios/article/view/11582

Pinto, L. (2015). Conflictos Ambientales y apropiación de territorios rurales en Brasil y Argentina, un análisis a partir de los actores sociales involucrados: estudio comparativo de la acción internacional de La Vía Campesina [Tesis de Doctorado, Universidad Nacional de Quilmes] http://ridaa.unq.edu.ar/handle/20.500.11807/104

Seoane, J., Taddei, E., y Algranati, C. (2018). Movimientos sociales e internacionalismo en Nuestra América: del ciclo de conflictividad y cambios sociopolíticos a la ofensiva neoliberal actual. Luxemburg.

Seoane, J., Taddei, E., y Algranatti, C. (2009). El concepto “movimiento social” a la luz de los debates y la experiencia latinoamericana reciente. Instituto de Investigaciones Sociales, Universidad Autónoma de México.

Tarrow, S. (1997). El poder en movimiento. Los movimientos sociales, la acción colectiva y la política. Alianza.

Touraine, A. (1991). Los Movimientos Sociales. Almagesto.

\section{AUTOR}

Oscar Soto. Licenciado en Ciencia Política y Administración Pública y Maestro en Estudios Latinoamericanos por la Universidad Nacional de Cuyo. Docente en la catedra Teoría Política de la Licenciatura en Trabajo Social (FCPyS). Becario de CONICET y doctorando en Ciencias Sociales en la Universidad Nacional de Cuyo.

\section{Conflicto de intereses}

El auto informa ningún conflicto de interés posible.

\section{Financiamiento}

No existió asistencia financiera de partes externas al presente artículo.

\section{Agradecimientos}

A Suyai por sus aportes.

Sobre el artículo.

Este artículo es producto del trabajo en un seminario cursado de la Maestría en Estudios Latinoamericanos. 